\title{
Upaya Pengendalian Genangan Berbasis Konservasi di Kecamatan Blimbing Kota Malang
}

\author{
Fahma Furqani $^{1 *}$, Ussy Andawayanti ${ }^{1}$, M. Janu Ismoyo ${ }^{1}$ \\ ${ }^{1}$ Jurusan Teknik Pengairan, Fakultas Teknik, Universitas Brawijaya \\ Jl. MT. Haryono No. 167, Malang, 65145, Indonesia
}

*Korespondensi Email: furqani.fahma@yahoo.co.id

\begin{abstract}
A puddle is a condition where the water stops flowing in a certain area that is not a water body. In theory, a boezem building in Blimbing Village can help control the inundation and soak it into the ground. However, until now, there are still cases of inundation in Blimbing District. Therefore, this study aims to determine the existing conditions of drainage and boezem, and plan alternative buildings that can help the performance of boezem as a conservation-based inundation controller. From the analysis, the existing drainage and boezem cannot fully accommodate the design discharge. The inability of the existing boezem to accommodate all the total design flows leaves an inundation of $2,076 \mathrm{~m}^{3} / \mathrm{s}$ with a 2 -year return period and $2,551 \mathrm{~m}^{3} / \mathrm{s}$ with a 5-year return period. Two conservation-based alternatives are offered to control the inundation. Based on technical and economic analysis, a 595-unit infiltration well was chosen in the boezem catchment area with total flood reduction of $22 \%$ and Rp's total fund. 3,276,869,973.16.
\end{abstract}

Keywords: Bozem, Conservation, Infiltration Well, Puddle, Rainwater Collection

Abstrak: Genangan merupakan kondisi dimana air berhenti mengalir pada suatu area tertentu yang bukan merupakan badan air. Adanyan bangunan boezem di Kelurahan Blimbing secara teori dapat membantu mengendalikan genangan dan meresapkannya ke dalam tanah, namun sampai saat ini masih terjadi kasus-kasus genangan di Kecamatan Blimbing. Maka dari itu penelitian ini bertujuan untuk mengetahui kondisi eksisting drainase dan boezem serta merencanakan alternatif bangunan yang dapat membantu kinerja boezem sebagai pengendali genangan berbasis konservasi. Dari hasil analisa, drainase dan boezem eksisting tidak dapat sepenuhnya menampung debit rancangan. Ketidakmampuan boezem eksisting dalam menampung seluruh debit rancangan total menyisakan genangan sebesar $2.076 \mathrm{~m}^{3} / \mathrm{dt}$ dengan kala ulang 2 tahun dan $2.551 \mathrm{~m}^{3} / \mathrm{dt}$ dengan kala ulang 5 tahun. Untuk mengendalikan genangan tersebut ditawarkan dua alternatif berbasis konservasi. Berdasarkan analisa teknis dan ekonimis dipilihlah pembangunan 595-unit sumur resapan pada catchment area boezem yang dapat mereduksi $22 \%$ debit genangan dengan total dana sebesar Rp. $3,276,869,973.16$.

Kata kunci: Boezem, Genangan, Konsevasi, Penampung Air Hujan, Sumur Resapan 


\section{Pendahuluan}

Genangan merupakan kondisi dimana air berhenti mengalir pada suatu area tertentu yang bukan merupakan badan air [1]. Tercatat genangan sering terjadi di Kecamatan Blimbing dan sekitarnya dengan ketinggian rata-rata $0.5 \mathrm{~m}$. Hal ini terjadi ketika hujan yang turun dengan debit yang besar dan saluran drainase yang tidak mampu menampung semua beban air hujan. Konsep drainase konvensional selama ini adalah melewatkan limpasan air hujan secepatnya melalui saluran-saluran yang ada ke sungai [2]. Hal ini dapat menyebabkan melimpasnya air di bagian hilir. Oleh karena itu, akhir-akhir ini sudah banyak dikembangkan konsep yang ramah lingkungan, seperti konservasi. Konservasi merupakan upaya untuk memanfaatkan sebanyak-banyaknya limpasan air hujan sebelum dibuang ke saluran. Konservasi bisa dalam bentuk pemakaian air hujan maupun peresapan air hujan sebagai cadangan air tanah [3].

Warga sekitar Kecamatan Blimbing, perangkat kelurahan, serta Dinas PUPR Kota Malang bekerjasama dalam mengendalikan genangan air yang tergenang di Kecamatan Blimbing dengan membangun sebuah boezem. Boezem ini dibangun di utara Pasar Blimbing dengan bentuk cekungan yang diberi perkuatan beton. Menurut warga sekitar, fungsi utama dari boezem ini adalah untuk meresapkan air ke dalam tanah sebagai cadangan air tanah. Selain itu, warga sekitar juga berpendapat boezem ini telah membantu mengurangi genangan air. Adanyan bangunan boezem di Kelurahan Blimbing secara teori dapat membantu mengendalikan genangan dan meresapkannya ke dalam tanah, namun sampai saat ini masih terjadi kasus-kasus genangan di Kecamatan Blimbing. Hal ini menandakan belum efektifnya fungsi boezem dalam menampung dan menyerapkan debit banjir yang ada. Penelitian ini bertujuan untuk mengetahui kondisi eksisting drainase dan boezem serta merencanakan berbagai alternatif bangunan yang dapat membantu kinerja boezem sebagai pengendali genangan berbasis konservasi.

\section{Bahan dan Metode}

\subsection{Bahan}

Dalam studi ini dibutuhkan data guna menunjang analisa. Data-data yang digunakan dalam studi ini berupa data primer dan data sekunder. Data primer merupakan data yang diperoleh langsung dengan survey lapangan. Data primer dibutuhkan data saluran drainase eksisting beserta dimensinya, data ini dibutuhkan untuk menentukan catchment area boezem dan volume saluran drainase eksisting. Kemudian dibutuhkan pula data dimensi boezem eksisting untuk menentukan volume boezem eksisiting.

Sedangkan data sekunder merupakan data yang diperoleh dari beberapa sumber yang bisa dipertanggungjawabkan kebenarannya. Dibutuhkan data curah hujan dari beberapa stasiun hujan di sekitar catchmen area boezem selama 11 tahun, diantaranya data curah hujan St. Blimbing yang bersumber dari UPT PSDA di Kediri Korwil Malang, data curah hujan St. Klimatologi Karangploso yang bersumber dari data online pusat database BMKG, dan data curah hujan St. Laboratorium Hidrologi Universitas Brawijaya yang bersumber dari Laboratorium Hidrologi Universitas Brawijaya. Data curah hujan ini diperlukan untuk menentukan debit rancangan daerah studi dengan kala ulang 2 dan 5 tahun. Data kependudukan Kota Malang tahun 2018 yang bersumber dari Kota Malang dalam Angka 2019 Untuk menentukan proyeksi penduduk dan debit air kotor pada catchment area boezem. Peta administrasi Kota Malang untuk menentukan catchment area boezem. Peta jenis tanah Kota Malang yang bersumber dari Kementrian Pekerjaan Umum, 2019 Untuk menentukan harga koefisien 
permeabilitas. Dan terakhir Data HSPK Kota Malang 2019 yang bersumber dari Keputusan Walikota Malang Untuk menentukan RAB.

\subsection{Metode}

Dengan cara studi lapangan ditentukanlah lokasi studi penelitian yang merupakan catchment area boezem. Catchment area boezem mencakup 3 kelurahan yaitu Kelurahan Blimbing, Tunjungsekar dan Mojolangu dengan luas yaitu 10.062 ha. Peta catchment area boezem dapat dilihat pada Gambar 1 .

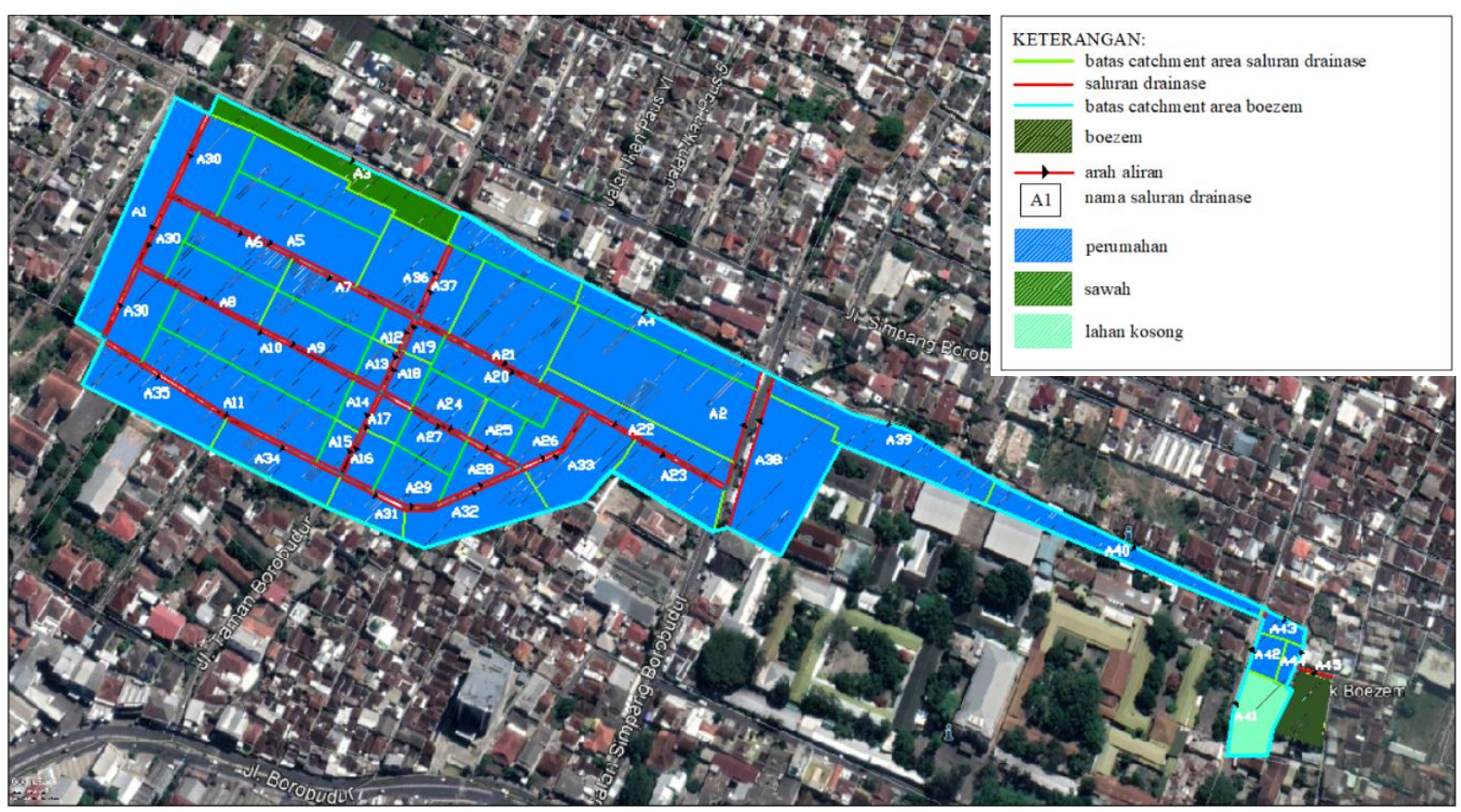

Gambar 1: Peta Catchment Area Boezem

Setelah lokasi studi sudah ditentukan, dilakukanlah beberapa analisa yaitu analisa hidrologi, analisa debit rancangan, analisa kapasitas tampungan, penentuan alternatif pengendalian genangan dan analisa keefektivan alternatif.

\subsection{Persamaan}

\subsubsection{Analisa Hidrologi}

Curah hujan rerata daerah metode Poligon Thiessen menurut dapat dihitung dengan persamaan berikut [4].

$$
\bar{d}=\frac{A_{1} d_{1}+A_{2} d_{2}+\cdots+A_{n} d_{n}}{A_{1}+A_{2} \cdots+A_{n}} \quad \text { Pers. } 1
$$

Untuk mendapatkan distribusi frekuensi yang sesuai dengan data yang tersedia untuk perhitungan curah hujan rancangan, digunakan analisa frekuensi. Dipilihlah Distribusi Log Pearson III dikarenakan harga Ck dan Cs bebas [5]. Menghitung nilai ekstrim, dengan rumus:

$$
\log X=\overline{\log X}+G * S \quad \text { Pers. } 2
$$




\subsubsection{Analisa Debit Rancangan}

Debit rancangan adalah besaran debit maksimum pada kala ulang tertentu, yang terjadi di suatu titik tinjau tertentu. Bentuk perumusan dari debit rancangan adalah sebagai berikut:

$$
Q_{r}=Q_{a h}+Q_{a k} \quad \text { Pers. } 3
$$

Metode yang digunakan untuk menghitung debit air hujan pada penelitian ini adalah Metode Rasional. Bentuk umum persamaannya adalah sebagai berikut:

$$
Q=0,278 . C . I . A \quad \text { Pers. } 4
$$

dengan:

$Q_{r} \quad=$ debit rancangan $\left(\mathrm{m}^{3} / \mathrm{dt}\right)$

$Q_{a h} \quad=$ debit air hujan $\left(\mathrm{m}^{3} / \mathrm{dt}\right)$

$Q_{a k} \quad=$ debit air kotor $\left(\mathrm{m}^{3} / \mathrm{dt}\right)$

$\mathrm{Q} \quad=$ debit limpasan $\left(\mathrm{m}^{3} / \mathrm{dt}\right)$

$\mathrm{C}=$ koefisien limpasan

I = intensitas hujan selama waktu tiba banjir $(\mathrm{mm} / \mathrm{jam})$

A $\quad=$ luas daerah $\left(\mathrm{km}^{2}\right)$

Perhitungan debit air kotor dapat dihitung dengan rumus:

$$
Q_{a k}=\frac{P_{n} \cdot q}{A} \quad \text { Pers. } 5
$$

Sedangkan pertumbuhan penduduk dihitung menggunakan Metode Geometrik. Pengukuran penduduk dengan metode ini tepat karena dalam kenyataannya pertumbuhan penduduk juga berlangsung terus menerus. Perhitungan dapat dilakukan dengan rumus [6]:

$$
\begin{array}{ll}
r=\frac{1}{\mathrm{t}} \operatorname{In}\left(\frac{\mathrm{P}_{\mathrm{t}}}{\mathrm{P}_{\mathrm{o}}}\right) & \text { Pers. 6 } \\
P_{n}=P_{o} \cdot e^{r . n} & \text { Pers. 7 }
\end{array}
$$

dimana:

$Q_{a k} \quad=$ debit air kotor (liter/ dt. $\left.\mathrm{km}^{2}\right)$

$P_{n} \quad=$ jumlah penduduk (orang)

A $\quad=$ luas daerah $\left(\mathrm{km}^{2}\right)$

$\mathrm{q} \quad=$ jumlah air buangan (liter/ orang . hari)

$=50-85 \%$ dari jumlah kebutuhan air tiap penduduk

$P_{n} \quad=$ jumlah penduduk pada tahun ke $\mathrm{n}$ (jiwa/tahun)

$P_{O} \quad=$ jumlah penduduk pada awal tahun (jiwa/tahun)

$\mathrm{e} \quad=$ bilangan logaritma

$\mathrm{n} \quad=$ interval waktu (tahun)

$\mathrm{r} \quad=$ angka pertumbuhan penduduk $(\%)$

2.3.3. Analisa Kapasitas Tampungan [7]:

Untuk mengetahui debit saluran dapat menggunakan rumus Manning, persamaan sebagai berikut

$$
Q=\mathrm{A}_{\mathrm{sal}} . v_{\mathrm{sal}} \quad \text { Pers. } 8
$$




$$
v_{s a l}=\frac{1}{n} \cdot R^{2 / 3} \cdot S^{1 / 2}
$$

Pers. 9

dengan:

$$
\begin{array}{ll}
\mathrm{Q} & =\text { debit yang ditampung }(\mathrm{m} 3 / \mathrm{dt}) \\
\text { Asal } & =\text { luas saluran }(\mathrm{m} 2) \\
\mathrm{vsal} & =\text { kecepatan aliran }(\mathrm{m} / \mathrm{dt}) \\
\mathrm{n} & =\text { koefisien manning } \\
\mathrm{R} & =\text { jari-jari hidrolis }(\mathrm{m}) \\
\mathrm{S} & =\text { kemiringan saluran }
\end{array}
$$

Sedangkan untuk mengetahui volume resap pada boezem, dapat menggunakan pendekatan sumur resapan dengan rumus sebagai berikut [8]:

$$
\begin{array}{rlr}
\mathrm{V}_{\text {rsp }} & =\frac{t_{c}}{24} \cdot A_{\text {total }} \cdot K & \text { Pers. } 10 \\
\mathrm{t}_{\mathrm{c}} & =0,9 \frac{R^{0,92}}{60} & \text { Pers. } 11
\end{array}
$$

dimana:

$\mathrm{V}_{\mathrm{rsp}} \quad=$ Volume air hujan yang meresap (m3)

$\mathrm{t}_{\mathrm{c}} \quad=$ durasi hujan efektif (jam)

$\mathrm{R}=$ tinggi hujan harian rata-rata ( $\mathrm{m} 2 /$ hari $)$

Atotal = luas dinding sumur + luas alas sumur (m2)

$\mathrm{K}=$ koefisien permeabilitas tanah $(\mathrm{m} / \mathrm{hari})$

\subsubsection{Alternatif Pengendalian Genangan}

Tujuan sistem drainase dengan konsep konservasi adalah untuk memperbanyak air yang tersimpan dalam tanah. Biasanya dilakukan dengan cara menahan air limpasan yang datang. Kemudian membiarkan air yang tertahan itu meresap ke dalam tanah, selanjutnya air yang terseisa secara pelahanlahan dialirkan ke sungai. Bangunan atau sarana yang umum sebagai peresapan air hujan adalah saluran drainase tanpa perkuatan, saluran drainase tanpa perkerasan dengan perlakuan, parit infiltrasi, saluran drainase pracetak berlubang, lubang resapan biopori, sumur resapan, kolam tampungan resapan, kawasan perlindungan air tanah dan panen air hujan.

Untuk menghitung air yang melimpas dari atap, digunakan Metode Rasional (Pers. 4), sedangkan untuk menghitung tinggi sumur resapan digunakan persamaan berikut [9]:

$$
H=\frac{Q}{\omega \pi r K} \quad \text { Pers. } 12
$$

Harga $\omega=2$, untuk sumur kosong berdinding kedap air atau sumur tanpa dinding dengan batu pengisi dan harga $\omega=5$, untuk sumur kosong berdinding porus.

dengan:

$$
\begin{array}{ll}
\mathrm{H} & =\text { kedalaman sumur }(\mathrm{m}) \\
\mathrm{R} & =\text { radius sumur }(\mathrm{m}) \\
\mathrm{K} & =\text { koefisien permeabilitas tanah }(\mathrm{m} / \mathrm{jam}) \\
\mathrm{Q} & =\text { debit andil banjir }(\mathrm{Q}=\text { C.I.A) }(\mathrm{m} 3 / \mathrm{jam})
\end{array}
$$




\section{Hasil dan Pembahasan}

\subsection{Analisa Hidrologi}

Analisa hidrologi adalah salah satu tahap awal dalam perencanaan bangunan air. Pada studi ini dilakukan pengamatan pada 3 stasiun hujan yaitu Stasiun Hujan Blimbing, Stasiun Klimatologi Karangploso dan Stasiun Hujan Lab. Hidrologi Universitas Brawijaya. Ketiga stasiun ini merupakan stasiun hujan terdekat dari DAS pengamatan. Setelah dilakukan uji kelayakan data dengan uji kurva massa ganda, uji outlier dan uji stasioner kemudian untuk mengetahui pengaruh setiap pos hujan terhadap curah hujan rerata daerah pengamatan dilakukanlah analisa hujan rerata daerah dengan Metode Poligon Thiessen. Metode ini memberikan hasil yang teliti dibandingkan dengan metode rata-rata aljabar, namun penentuan titik pengamatan akan mempengaruhi ketelitian yang didapat. Dari hasil Poligon Thiessen pada daerah studi didapatkan hanya satu stasiun hujan yang mempengaruhi DAS pengamatan. Oleh karena itu didapatkan curah hujan rerata DAS pengamatan seperti pada Tabel 2.

Tabel 1: Curah Hujan Rerata Daerah

\begin{tabular}{ccc}
\hline No. & Tahun & $\begin{array}{c}\text { Curah Hujan Rerata } \\
(\mathbf{m m})\end{array}$ \\
\hline \hline 1 & 2009 & 70,03 \\
2 & 2010 & 109,38 \\
3 & 2011 & 66,45 \\
4 & 2012 & 81,16 \\
5 & 2013 & 92,19 \\
6 & 2014 & 76,44 \\
7 & 2015 & 94,15 \\
8 & 2016 & 62,77 \\
9 & 2017 & 102,00 \\
10 & 2018 & 95,14 \\
11 & 2019 & 82,00 \\
\hline
\end{tabular}

Setelah didapatkan curah hujan rerata daerah, dilakukan analisa frekuensi dengan Metode Log Pearson III untuk mendapatkan curah hujan maksimum, didapatkan data curah hujan rancangan sebagai berikut:

Tabel 2: Perhitungan Curah Hujan Rancangan Distribusi Log Pearson III

\begin{tabular}{ccccccc}
\hline $\begin{array}{c}\mathbf{T r} \\
(\mathbf{t a h u n})\end{array}$ & $\begin{array}{c}\mathbf{P r} \\
(\boldsymbol{\%})\end{array}$ & $\mathbf{G}$ & $\mathbf{S ~ L o g} \mathbf{X}$ & $\overline{\log \boldsymbol{X}}$ & $\begin{array}{c}\log \mathbf{X}_{\text {rancangan }} \\
(\mathbf{m m})\end{array}$ & $\begin{array}{c}\mathbf{X}_{\text {rancangan }} \\
(\mathbf{m m})\end{array}$ \\
\hline 2 & 50 & 0,028 & 0,079 & 1,921 & 1,924 & 83,890 \\
5 & 20 & 0,849 & 0,079 & 1,921 & 1,988 & 97,324 \\
\hline
\end{tabular}

Perencanaan drainase perkotaan, memerlukan besaran curah hujan harian maksimum dengan kala ulang (Tr) tertentu. Berdasarkan luas daerah pengaliran saluran (DPSal) atau luas catchment area boezem yaitu 10.062 ha, (10-100 ha) dengan tipologi kota termasuk kota besar, maka kala ulang yang digunakan adalah 2 dan 5 tahun [10]. Kemudian dilakukan analisa kesesuaian distribusi dengan Uji Chi-Square dan Uji Smirnov Kolmogorov. Untuk kedua uji ini didapatkan bahawa hasil curah hujan rancangan dengan Metode Log Pearson III dapat diterima. 


\subsection{Analisa Debit Rancangan}

Analisa Debit Rancangan ini dilakukan pada setiap saluran drainase. Skema drainase ditunjukkan pada Gambar 3.

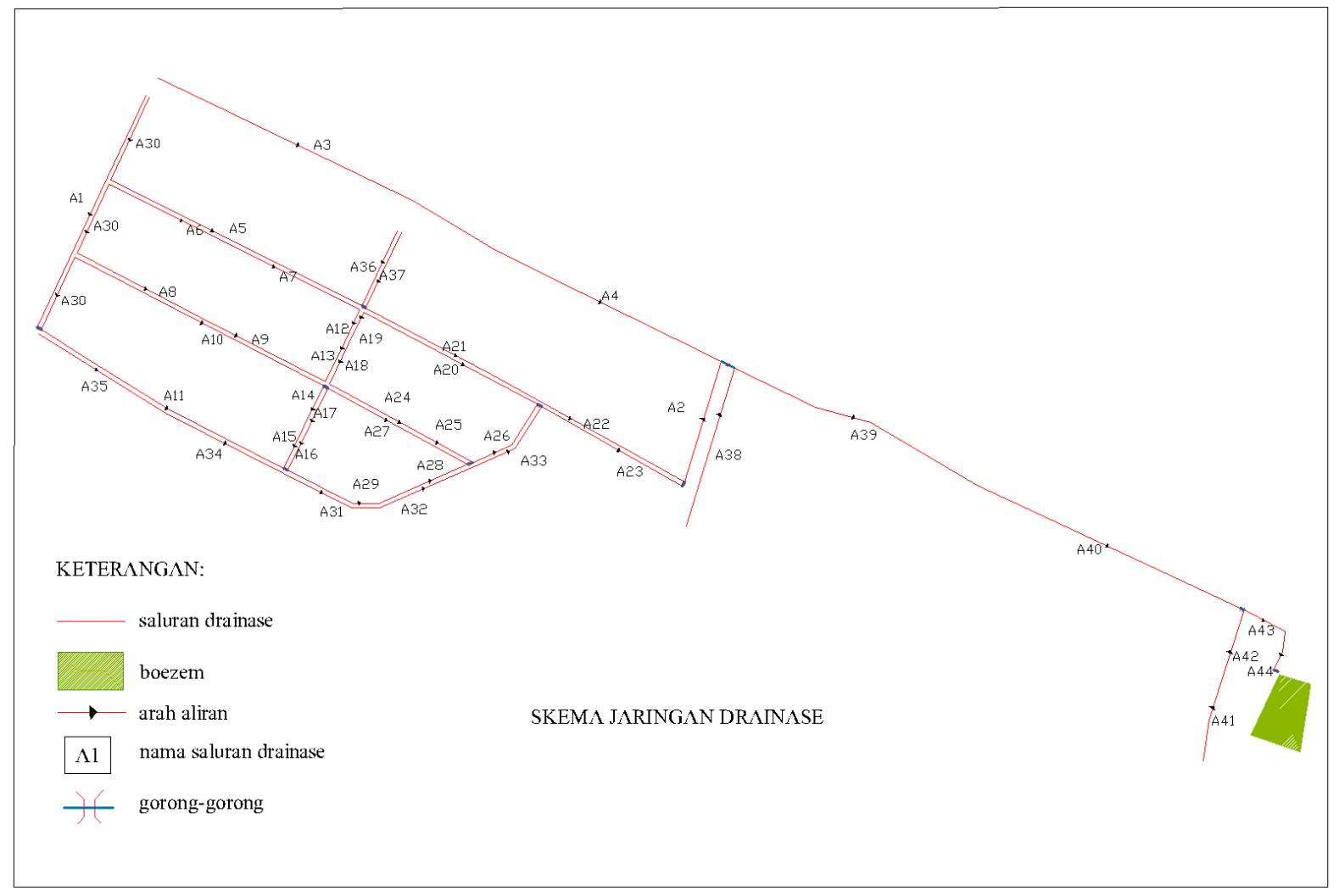

\section{Gambar 2: Skema Jaringan Drainase}

Skema jaringan drainase ini sangat dibutuhkan untuk menentukan debit rancangan $\left(Q_{r}\right)$. Perhitungan debit rancangan per saluran dapat dilakukan dengan menjumlahkan debit air hujan $\left(Q_{a h}\right)$ dengan debit air kotor $\left(Q_{a k}\right)$ terlebih dahulu. Kemudian dilakukan penelusuran arah aliran debit rancangan yang disesuaikan dengan kondisi topografi.

\subsection{Kapasitas Tampungan}

a. Evaluasi Kapasitas Saluran Drainase Eksisting

Saluran drainase dapat dikatakan layak apabila debit rancangan per saluran lebih kecil dari kapasitas drainase per saluran (Qrs < Qds) sehingga debit rancangan dapat ditampung oleh drainase. Apabila tidak sesuai dengan kriteria tersebut, maka terjadilah genangan. Berikut hasil perhitungan evaluasi kapasitas saluran drainase eksisting terhadap debit rancangan per saluran dapat dilihat pada Tabel 4.

Dari hasil evaluasi drainase per saluran ini, didapatkan bahwa saluran drainase pada catchment area boezem yang terdiri dari 46 saluran, tidak dapat sepenuhnya menampung debit rancangan. Terdapat 15 saluran yang tidak memenuhi debit rancangan dengan kala ulang 2 tahun, dan 17 saluran yang tidak memenuhi dengan kala ulang 5 tahun. Dapat disimpulkan bahwa saluran drainase tersebut berpotensi untuk menimbulkan genangan. Oleh karena itu dibutuhkan alternatif pengendalian genangan dan pemeliharaan saluran drainase eksisting secara berkala agar dapat berfungsi. 
Tabel 3: Evaluasi Kapasitas Drainase per Saluran

\begin{tabular}{|c|c|c|c|c|c|c|}
\hline \multirow[t]{2}{*}{ Saluran } & \multicolumn{2}{|c|}{$\begin{array}{c}\text { Tr=2 Tahun } \\
\left(\mathrm{m}^{3} / \mathrm{dt}\right)\end{array}$} & \multirow[t]{2}{*}{ Keterangan } & \multicolumn{2}{|c|}{$\begin{array}{c}\text { Tr=5 Tahun } \\
\left(\mathrm{m}^{3} / \mathrm{dt}\right)\end{array}$} & \multirow[t]{2}{*}{ Keterangan } \\
\hline & Qrs & $\mathbf{Q}_{\mathrm{ds}}$ & & $Q_{\mathrm{rs}}$ & $\mathbf{Q}_{\mathrm{ds}}$ & \\
\hline$\overline{\mathrm{A1}}$ & 0.123 & 0.181 & Memenuhi & 0.143 & 0.476 & Memenuhi \\
\hline A2 & 2.984 & 0.141 & Tidak Memenuhi & 3.461 & 0.181 & Tidak Memenuhi \\
\hline A3 & 0.142 & 0.435 & Memenuhi & 0.164 & 0.141 & Memenuhi \\
\hline A4 & 0.348 & 0.543 & Memenuhi & 0.403 & 0.435 & Memenuhi \\
\hline A5 & 0.291 & 0.337 & Memenuhi & 0.338 & 0.543 & Tidak Memenuhi \\
\hline A6 & 0.077 & 0.159 & Memenuhi & 0.090 & 0.337 & Memenuhi \\
\hline A7 & 0.175 & 0.260 & Memenuhi & 0.203 & 0.159 & Memenuhi \\
\hline A8 & 0.195 & 0.483 & Memenuhi & 0.226 & 0.260 & Memenuhi \\
\hline A9 & 0.312 & 0.374 & Memenuhi & 0.362 & 0.483 & Memenuhi \\
\hline A10 & 0.164 & 0.277 & Memenuhi & 0.190 & 0.374 & Memenuhi \\
\hline A11 & 0.414 & 0.615 & Memenuhi & 0.481 & 0.277 & Memenuhi \\
\hline A12 & 0.203 & 0.095 & Tidak Memenuhi & 0.235 & 0.615 & Tidak Memenuhi \\
\hline A13 & 0.243 & 0.297 & Memenuhi & 0.282 & 0.095 & Memenuhi \\
\hline A14 & 0.041 & 0.411 & Memenuhi & 0.048 & 0.297 & Memenuhi \\
\hline A15 & 0.086 & 0.682 & Memenuhi & 0.099 & 0.411 & Memenuhi \\
\hline A16 & 0.106 & 0.703 & Memenuhi & 0.123 & 0.682 & Memenuhi \\
\hline A17 & 0.046 & 0.557 & Memenuhi & 0.053 & 0.703 & Memenuhi \\
\hline A18 & 0.074 & 0.398 & Memenuhi & 0.086 & 0.557 & Memenuhi \\
\hline A19 & 0.027 & 0.105 & Memenuhi & 0.032 & 0.398 & Memenuhi \\
\hline A20 & 0.132 & 0.778 & Memenuhi & 0.153 & 0.105 & Memenuhi \\
\hline A21 & 0.738 & 0.488 & Tidak Memenuhi & 0.856 & 0.778 & Tidak Memenuhi \\
\hline $\mathbf{A} 22$ & 0.833 & 0.360 & Tidak Memenuhi & 0.966 & 0.488 & Tidak Memenuhi \\
\hline $\mathbf{A} 23$ & 1.911 & 0.444 & Tidak Memenuhi & 2.217 & 0.360 & Tidak Memenuhi \\
\hline A24 & 0.163 & 0.669 & Memenuhi & 0.189 & 0.444 & Memenuhi \\
\hline A25 & 0.230 & 0.295 & Memenuhi & 0.267 & 0.669 & Memenuhi \\
\hline A26 & 1.238 & 0.228 & Tidak Memenuhi & 1.437 & 0.295 & Tidak Memenuhi \\
\hline A27 & 0.233 & 0.497 & Memenuhi & 0.270 & 0.228 & Memenuhi \\
\hline A28 & 0.716 & 0.029 & Tidak Memenuhi & 0.831 & 0.497 & Tidak Memenuhi \\
\hline A29 & 0.689 & 0.378 & Tidak Memenuhi & 0.799 & 0.029 & Tidak Memenuhi \\
\hline A30 & 0.121 & 0.215 & Memenuhi & 0.141 & 0.378 & Memenuhi \\
\hline A30a & 0.070 & 0.262 & Memenuhi & 0.081 & 0.215 & Memenuhi \\
\hline A30b & 0.097 & 0.204 & Memenuhi & 0.112 & 0.262 & Memenuhi \\
\hline A31 & 0.199 & 0.239 & Memenuhi & 0.231 & 0.204 & Memenuhi \\
\hline A32 & 0.274 & 0.028 & Tidak Memenuhi & 0.318 & 0.239 & Tidak Memenuhi \\
\hline A33 & 0.422 & 0.460 & Memenuhi & 0.489 & 0.028 & Tidak Memenuhi \\
\hline A34 & 0.301 & 0.947 & Memenuhi & 0.350 & 0.460 & Memenuhi \\
\hline A35 & 0.174 & 1.178 & Memenuhi & 0.202 & 0.947 & Memenuhi \\
\hline A36 & 0.118 & 0.256 & Memenuhi & 0.137 & 1.178 & Memenuhi \\
\hline A37 & 0.080 & 0.462 & Memenuhi & 0.093 & 0.256 & Memenuhi \\
\hline A38 & 0.210 & 0.155 & Tidak Memenuhi & 0.244 & 0.462 & Tidak Memenuhi \\
\hline A39 & 3.709 & 0.396 & Tidak Memenuhi & 4.303 & 0.155 & Tidak Memenuhi \\
\hline A40 & 3.811 & 0.189 & Tidak Memenuhi & 4.421 & 0.396 & Tidak Memenuhi \\
\hline A41 & 0.065 & 0.527 & Memenuhi & 0.075 & 0.189 & Memenuhi \\
\hline A42 & 0.093 & 0.033 & Tidak Memenuhi & 0.108 & 0.527 & Tidak Memenuhi \\
\hline $\mathbf{A 4 3}$ & 3.940 & 0.112 & Tidak Memenuhi & 4.570 & 0.033 & Tidak Memenuhi \\
\hline A44 & 3.966 & 0.111 & Tidak Memenuhi & 4.601 & 0.112 & Tidak Memenuhi \\
\hline
\end{tabular}

\section{b. Evaluasi Kapasitas Tampungan Boezem Eksisting}

Evaluasi kapasitas tampungan boezem eksisting adalah suatu evaluasi yang dilakukan dengan membandingan besarnya debit boezem total $(\mathrm{Qb})$ dengan debit rancangan total (Qrt) pada titik tinjau. Jika Qb < Qrt maka akan terjadi genangan dan perlu dilakukan perencanaan alternatif yang dapat mengendalikan genangan tersebut. Titik tinjau yang digunakan adalah pada saluran A44. Didapatkan 
Qb sebesar $1.890 \mathrm{~m}^{3} / \mathrm{dt}$ dan Qrt sebesar $3.966 \mathrm{~m}^{3} / \mathrm{dt}(\mathrm{Qb}<\mathrm{Qrt})$. Maka debit rancangan total tidak dapat ditampung sepenuhnya oleh boezem, dan terdapat genangan.

Tabel 4: Rekapitulasi Genangan

\begin{tabular}{ccc}
\hline Debit & Tr = 2 Tahun & Tr = 5 Tahun \\
\hline \hline Rancangan total $(\mathrm{Qrt})$ & $3.966 \mathrm{~m}^{3} / \mathrm{dt}$ & $4.601 \mathrm{~m}^{3} / \mathrm{dt}$ \\
Boezem $(\mathrm{Qb})$ & $1.890 \mathrm{~m}^{3} / \mathrm{dt}$ & $2.050 \mathrm{~m}^{3} / \mathrm{dt}$ \\
Genangan $(\mathrm{Qg})$ & $2.076 \mathrm{~m}^{3} / \mathrm{dt}$ & $2.551 \mathrm{~m}^{3} / \mathrm{dt}$ \\
\hline
\end{tabular}

\subsection{Pemilihan Alternatif}

Tabel 5: Pemilihan Alternatif sesuai Kondisi Daerah Studi

\begin{tabular}{|c|c|c|c|c|}
\hline No. & Jenis Konservasi & Ketentuan & Kondisi Wil. Studi & $\begin{array}{l}\text { Cocok/ } \\
\text { tidak }\end{array}$ \\
\hline 1. & $\begin{array}{l}\text { Saluran drainase } \\
\text { tanpa perkerasan }\end{array}$ & $\begin{array}{c}\text { Hanya cocok pada pemukiman dengan } \\
\text { kepadatan rendah (berdasarkan sub bab } \\
2.4 .1 \text {.) }\end{array}$ & $\begin{array}{l}\text { Kawasan pemukiman denga } \\
\text { kepadatan penduduk tinggi }\end{array}$ & $\mathrm{X}$ \\
\hline 2. & $\begin{array}{l}\text { Saluran drainase } \\
\text { tanpa perkerasan } \\
\text { dengan perlakuan }\end{array}$ & $\begin{array}{c}\text { Hanya cocok pada pemukiman dengan } \\
\text { kepadatan rendah (berdasarkan sub bab } \\
\text { 2.4.2.) }\end{array}$ & $\begin{array}{l}\text { Kawasan pemukiman denga } \\
\text { kepadatan penduduk tinggi }\end{array}$ & $\mathrm{X}$ \\
\hline 3. & Parit infiltrasi & $\begin{array}{l}\text { Kedalaman muka air tanah }<2 \mathrm{~m} \\
\quad \text { (berdasarkan sub bab 2.4.3.) }\end{array}$ & Kedalaman muka air tanah $>2 \mathrm{~m}$ & $\mathrm{X}$ \\
\hline 4. & $\begin{array}{l}\text { Saluran drainase } \\
\text { pracetak berlubang }\end{array}$ & $\begin{array}{l}\text { Debit air hujan dan debit air kotor } \\
\text { ditempatkan pada tempat yang berbeda }\end{array}$ & $\begin{array}{l}\text { Debit air hujan dan debit air kotor } \\
\text { ditempatkan pada saluran yang } \\
\text { sama }\end{array}$ & $\mathrm{X}$ \\
\hline 5. & $\begin{array}{l}\text { Lubang resapan } \\
\text { biopori }\end{array}$ & $\begin{array}{l}\text { Menggunakan sampah organic dan lubang } \\
\text { dengan kedalaman } 100 \mathrm{~cm}\end{array}$ & $\begin{array}{l}\text { Volume sebuah sumur resapan } \\
\text { dengan diameter } 1 \mathrm{~m} \text { dan } \\
\text { kedalaman } 3 \text { m akan setara } \\
\text { dengan } 300 \text { buah biopori }\end{array}$ & $\mathrm{X}$ \\
\hline 6. & Sumur resapan & $\begin{array}{c}\text { Cocok untuk kawasan perumahan dan tidak } \\
\text { memerlukan lahan yang luas. Kedalaman } \\
\text { muka air tanah }>2 \mathrm{~m} \text { (berdasarkan sub bab } \\
2.4 .6)\end{array}$ & Kedalaman muka air tanah $>2 \mathrm{~m}$ & $\mathrm{~V}$ \\
\hline 7. & $\begin{array}{l}\text { Penampung air } \\
\text { hujan }\end{array}$ & $\begin{array}{l}\text { Cocok untuk kawasan perumahan untuk } \\
\text { mengurangi anggaran air bersih dari PDAM }\end{array}$ & $\begin{array}{l}\text { Kawasan pemukiman denga } \\
\text { kepadatan penduduk tinggi }\end{array}$ & $\mathrm{V}$ \\
\hline
\end{tabular}

Tabel 6 menunjukkan uraian jenis-jenis perencanaan konservasi air yang disesuaikan dengan kondisi lokasi studi. Oleh karena itu dipilihlah dua alternatif yang akan direncanakan untuk mengatasi genangan pada catchment area boezem dan akan dilakukan analisa keefektivan alternatif untuk mementukan alternatif terbaik. Kedua alternatif itu adalah perencanaan sumur resapan dan erencanaan penampung air hujan.

\subsection{Analisa Teknis Alternatif}

Perencanaan dimensi alternatif menggunakan debit genagan dengan kala ulang 2 tahun. Hal ini dilakukan sesuai dengan ketentuan perencanaan alternatif yaitu sumur resapan [9]. Untuk mereduksi limpasan atau genangan yang terjadi di sekitar saluran drainase, maka alternatif dibangun di sekitar saluran drainase yaitu pada daerah tangkapan air saluran tersebut. 
a. Alternatif 1 (Perencanaan Sumur Resapan)

Perencanaan berdasarkan SNI 8456:2017

Luas bidang atap/ tadah (At)

$$
\begin{aligned}
& =156 \mathrm{~m}^{2} \\
& =83.890 \mathrm{~mm} \\
& =2 \mathrm{jam} \\
& =0.95
\end{aligned}
$$

Hujan rancangan (R)

Durasi hujan (t)

$\mathrm{C}_{\text {tadah }}$

Dimensi Sumur Resapan

Diameter sumur $\left(\mathrm{d}_{\text {sumur }}\right)$

$=0.6 \mathrm{~m}$

Koefisien permeabilitas (K)

$$
\begin{aligned}
& =3 \mathrm{~m} / \mathrm{hr}=0.125 \mathrm{~m} / \mathrm{jam} \\
& =2(\text { dinding tidak porus) }
\end{aligned}
$$

rumus rasional

Intensitas hujan (I)

$=\frac{R_{24}}{24}\left[\frac{24}{t_{c}}\right]^{\frac{2}{3}}$

$=\frac{83.890}{24}\left[\frac{24}{2}\right]^{\frac{2}{3}}$

$=18.321 \mathrm{~mm} / \mathrm{jam}$

$=0.0183 \mathrm{~m} / \mathrm{dt}$

Kapasitas sumur resapan (Q)

$=\mathrm{C} \times \mathrm{I} \times \mathrm{A}_{\text {tadah }}$

$=0.95 \times 0.0183 \times 156$

$=2.713 \mathrm{~m}^{3} / \mathrm{jam}$

$\mathrm{H}$

$$
\begin{aligned}
& =\frac{Q}{\omega \pi r K} \\
& =\frac{{ }_{2.713}}{2.3 .140 .60 .125} \\
& =5.76 \mathrm{~m}
\end{aligned}
$$$$
=6 \mathrm{~m}
$$

Total debit rancangan yang dapat direduksi

$$
\begin{aligned}
& \text { Jumlah total unit rumah } \quad=595 \text { unit } \\
& \text { Debit sumur resapan }(\mathrm{Q}) \quad=2.713 \mathrm{~m}^{3} / \mathrm{jam} \\
& =0.00007543 \mathrm{~m}^{3} / \mathrm{dt} \\
& \text { Total debit yang direduksi }\left(\mathrm{Q}_{\text {reduksi }}\right) \quad=\text { Jumlah total unit rumah } \mathrm{x} Q \\
& =595 \times 0.00007543 \\
& =0.448 \mathrm{~m}^{3} / \mathrm{dt}
\end{aligned}
$$

Persentase reduksi terhadap debit genangan

$$
\begin{aligned}
\%_{\text {reduksi }} & =\left(\mathrm{Q}_{\text {reduksi }} / \mathrm{Q}_{\mathrm{g}}\right) \times 100 \% \\
& =(0.448 / 2.076) \times 100 \% \\
& =22 \%
\end{aligned}
$$

b. Alternatif 2 (Perencanaan Penampung Air Hujan)

Intensitas hujan (I)

$$
\begin{aligned}
& =\frac{R_{24}}{24}\left[\frac{24}{t_{c}}\right]^{\frac{2}{3}} \\
& =\frac{83.890}{24}\left[\frac{24}{2}\right]^{\frac{2}{3}} \\
& =18.321 \mathrm{~mm} / \mathrm{jam} \\
& =0.0183 \mathrm{~m} / \mathrm{dt} \\
& =\mathrm{C} \times \mathrm{I} \times \mathrm{A}_{\text {tadah }} \\
& =0.95 \times 0.0183 \times 156 \\
& =2.713 \mathrm{~m}^{3} / \mathrm{jam}
\end{aligned}
$$

Direncanakan tanki ukuran $1 \mathrm{~m}^{3}$

Total debit rancangan yang dapat direduksi 
Jumlah total unit rumah

Debit penampung air hujan $(\mathrm{Q})$

Total debit yang direduksi ( $\left.\mathrm{Q}_{\text {reduksi }}\right)$

$$
\begin{aligned}
& =595 \text { unit } \\
& =2.713 \mathrm{~m}^{3} / \mathrm{jam} \\
& =0.00007543 \mathrm{~m}^{3} / \mathrm{dt} \\
& =\text { Jumlah total unit rumah } \times \mathrm{Q} \\
& =595 \times 0.00007543 \\
& =0.448 \mathrm{~m}^{3} / \mathrm{dt}
\end{aligned}
$$

Persentase reduksi terhadap debit genangan

$$
\begin{aligned}
\%_{\text {reduksi }} & =\left(Q_{\text {reduksi }} / \mathrm{Q}_{\mathrm{g}}\right) \times 100 \% \\
& =(0.448 / 2.076) \times 100 \% \\
& =22 \%
\end{aligned}
$$

\subsection{Analisa Ekonomis Alternatif}

Analisa ini meliputi perhitungan Analisa Harga Satuan Pekerjaan (AHSP) yang koefisiennya telah disesuaikan dengan Peraturan Menteri Pekerjaan Umum dan Perumahan Rakyat No. 28/PRT/M/2016 dan harga satuan Kota Malang tahun 2019. Setelah mengetahui analisa harga satuan pekerjaan yang dibutuhkan, selanjutnya dihitung Bill of Quantity (BOQ) untuk mendapatkan volume. Harga satuan dan volume inilah yang nantinya dipaparkan perhitungannya pada RAB.

Biaya pembangunan satu unit Alternatif 1 membutuhkan dana sebesar Rp. 5,507,344.49 dan pembangunan satu unit Alternatif 2 membutuhkan dana sebesar Rp 5,723,792.40. Sehingga total dana yang dibutuhkan untuk pembangunan 595 unit Alternatif 1 dan 2 sebagai berikut:

Total dana yang dibutuhkan untuk membangun 595-unit alternatif 1 adalah:

Jumlah unit rumah x Biaya 1 unit $\quad=595 \times$ Rp. 5,507,344.49

$$
=\text { Rp. 3,276,869,973.16 }
$$

Total dana yang dibutuhkan untuk membangun 595-unit alternatif 2 adalah:

Jumlah unit rumah $\times$ Biaya 1 unit $\quad=595 \times \operatorname{Rp~5,723,792.40~}$

$=$ Rp. $3,418,972,605 \cdot 65$

\subsection{Analisa Keefektivan Alternatif}

Dari analisa teknis dan ekonomis masing-masing alternatif, berikut rekap pada Tabel 7.

Tabel 6: Rekapitulasi Analisa Keefektivan Alternatif

\begin{tabular}{ccc}
\hline Alternatif & Analisa Teknis (\%) & Analisa Ekonimis (Rp.) \\
\hline Alternatif 1 (Sumur Resapan) & 22 & $3,276,869,973.16$ \\
Alternatif 2 (PAH) & 22 & $3,418,972,605.65$ \\
\hline
\end{tabular}

Dari Tabel 7 dipilihlah Alternatif 1 yaitu melakukan pembangunan 595-unit sumur resapan pada catchment area boezem karena dapat mereduksi $22 \%$ debit genangan dengan total dana yang lebih murah.

\section{Kesimpulam}

Drainase dan boezem eksisting tidak dapat sepenuhnya menampung debit rancangan. Ketidakmampuan boezem eksisting dalam menampung seluruh debit rancangan total menyisakan genangan sebesar $2.076 \mathrm{~m}^{3} / \mathrm{dt}$ dengan kala ulang 2 tahun dan $2.551 \mathrm{~m}^{3} / \mathrm{dt}$ dengan kala ulang 5 tahun. Untuk mengendalikan genangan tersebut ditawarkan dua alternatif berbasis konservasi yaitu 
perencanaan sumur resapan dan penampung air hujan. Berdasarkan analisa teknis dan ekonimis dipilihlah Alternatif 1 yaitu pembangunan 595-unit sumur resapan pada catchment area boezem yang dapat mereduksi $22 \%$ debit genangan dengan total dana sebesar Rp. 3,276,869,973.16. Untuk menyelesaikan permasalahan genangan ini dibutuhkan koordinasi yang bai kantar semua pihak. Selain itu disamping merencanakan bangunan alternatif berbasis konservasi, genangan dapat lebih dikendaliakan dengan melakukan perlakuan dan perawatan pada saluran drainase eksisting.

\section{Ucapan Terimakasih}

Ucapan terimakasih kepada kepada Jurusan Teknik Pengairan Fakultas Teknik Universitas Brawijaya untuk dukungan yang telah diberikan. Selanjutnya ucapan terimakasih kepada Bapak Roni Kuncoro, S.STP. selaku Lurah Kelurahan Blimbing Kota Malang beserta jajaran dan warganya yang telah mengijinkan penulis untuk melakukan penelitian pada lokasi studi, berkunjung dan mengambil data primer. Kemudian ucapan terimakasih kepada UPT PSDA di Kediri Korwil Malang serta Dinas Pekerjaan Umum, Perumahan dan Pengawasan Lingkungan bagian drainase yang telah memberikan informasi dan data terkait penelitian ini.

\section{Daftar Pustaka}

[1] D. A. Kusumadewi, "Arahan Spasial Teknologi Drainase untuk Mereduksi Genangan di Sub Daerah Aliran Sungai Watu," Jurnal Teknik Pengairan, Vols. Volume 3, Nomor 2, p. 258-276, 2012.

[2] E. S. Pranoto, "Upaya Penanggulangan Genangan dan Peningkatan Resapan Air Menggunangan Underdrain Box Storage di Kawasan Kampus Universitas Brawijaya," Universitas Brawijaya, Malang, 2013.

[3] Suhardjono, Rancangan Drainase, Buku Ajar Tidak Dipublikasikan. Malang: Universitas Brawijaya, 2013.

[4] L. M. Limantara, Hidrologi Praktis, Bandung: Lubuk Agung, 2010.

[5] T. U. Handayani, " Studi Alternatif Perencanaan Buangan Akhir pada Sistem Drainase Kota Palangka Raya untuk Mengurangi Genangan," Universitas Brawijaya, Malang, 2014.

[6] Hartati, Indrawati, R. Sitepu and N. Tamba, "Prosoding Seminar Sains Matematika Informatika dan Aplikasinya IV," Metode Geometri, Metode Aritmatika dan Metode Eksponensial untuk Memproyeksikan Penduduk Provinsi Sumatera Selatan, pp. 2086-2342, 2016.

[7] B. Triatmodjo, Hidraulika II, Yogyakarta: Beta Offset, 1993.

[8] SNI 03-2453-2002, Tata Cara Perencanaan Sumur Resapan Air Hujan untuk Lahan Pekarangan, Jakarta: BSNI, 2002.

[9] SNI 8456:2017, Sumur dan parit resapan air hujan, Jakarta: BSNI, 2017.

[10] Peraturan Menteri Pekerjaan Umum, "Nomor 12/PRT/M/2014," Lampiran I Tentang Penyelenggaraan Sistem Drainase Perkotaan, pp. 1-116, 2014. 